\title{
What do we (do not) know about the use of cone beam computed tomography in endodontics? A thematic series with a call for scientific evidence
}

\author{
Kıvanç Kamburoğlu ${ }^{1 *}$, Igor Tsesis ${ }^{2}$ and Eyal Rosen ${ }^{2}$
}

\begin{abstract}
Cone beam computed tomography (CBCT) has become a common diagnostic method in endodontics. However, the current literature provides insufficient information about different aspects that are related to the use of CBCT, such as: the efficacy of CBCT to support the practitioner's clinical decision making and to affect treatment outcomes; about the required training of the practitioner so he can efficiently examine the entire region that appears in the CBCT scan and diagnose abnormalities or possible pathologies; and on the long-term health risks associated with the use of CBCT in endodontics. In addition, CBCT has the strong potential to be used for accurate diagnosis of complete and uneventful healing. In this thematic series, we call for manuscripts that discuss aspects of the use of CBCT in endodontics.
\end{abstract}

\section{Introduction}

The introduction of cone beam computed tomography (CBCT) imaging had significant effects on the daily practice of endodontics (Rosen et al. 2017; Rosen et al. 2015; Kumar et al. 2015; AAE and AAOMR Joint Position Statement 2015; AAOMR and AAE 2010). It is generally accepted that $\mathrm{CBCT}$ should not be used routinely in endodontics due to its excessive radiation dose compared to intraoral radiography (Rosen et al. 2015; AAE and AAOMR Joint Position Statement 2015; AAOMR and AAE 2010; Patel et al. 2015). However, it seems that CBCT use expended to almost every daily endodontic procedure (Rosen et al. 2017; Metska et al. 2014; Liang et al. 2013; Jeger et al. 2012; Janner et al. 2011; Ustun et al. 2016). This increased usage of CBCT in endodontic practices raises questions regarding what do we actually know about the benefits and risks of $\mathrm{CBCT}$ use for endodontic proposes. In this thematic series, we call for manuscripts that discuss different aspects of the use of $\mathrm{CBCT}$ in endodontics.

\footnotetext{
*Correspondence: dtkivo@yahoo.com; kamburogluk@dentistry.ankara.edu.tr ${ }^{1}$ Department of Dentomaxillofacial Radiology, Faculty of Dentistry, Ankara University, 06500 Beşevler, Çankaya, Ankara, Turkey

Full list of author information is available at the end of the article
}

\section{What do we (do not) know about the benefits of CBCT to the endodontic patient?}

The benefit of a diagnostic imaging should be estimated by its diagnostic efficacy that is "the probability of benefit to individuals from a system or test under ideal conditions of use" (Rosen et al. 2015; Krupinski and Jiang 2008). A common misunderstanding is that a "good" diagnostic efficacy means providing remarkable images of sufficient quality (Rosen et al. 2017; EUROPEANCOMMISSION 2012; Fryback and Thornbury 1991). The basis for this misunderstanding relies in the disregard of the wider clinical context (Rosen et al. 2017). For example, disregarding additional valuable diagnostic information that may have already been acquired before the endodontic procedure (e.g., by previous intraoral radiographs together with a meticulous clinical examination (AAOMR and AAE 2010; ADA 2012; Carrotte 2004; Ee et al. 2014; Mota de Almeida et al. 2015)) or during the procedure (e.g., by the use of magnification and illumination devices to asses complex anatomy (Weinstein et al. 2010; Del Fabbro et al. 2015). This preoperative and intra-operative acquired information may provide all the necessary information to support the practitioner's clinical decision making and therefore may 
lead to the conclusion that CBCT is not necessary (Rosen et al. 2017). In addition, there is fundamental question of what would be the ultimate benefit of this information, if attained by the CBCT?

In order to assess the ultimate benefit of an imaging modality, Fryback and Thornbury (1991) developed a diagnostic efficacy hierarchical model (Rosen et al. 2015). It includes several levels of imaging efficacy that for simplicity can be categorized into: technical efficacy (considered as the inferior levels and assess the technical quality of the images or the diagnostic accuracy associated with interpretation of the images) and to clinical efficacy (considered as the superior levels and asses the efficacy of the evaluated imaging modality to support the practitioner's clinical decision making and to improve treatment outcomes) (Rosen et al. 2017; Rosen et al. 2015; Fryback and Thornbury 1991; Matzen and Wenzel 2014). This model has been used in recent years also in dental research to evaluate the diagnostic efficacies of CBCT (Rosen et al. 2017; Rosen et al. 2015; EUROPEANCOMMISSION 2012; Pittayapat et al. 2014; Kim et al. 2011; Kaeppler et al. 2013). In endodontics, a recent systematic review of the literature (Rosen et al. 2015) used this model to evaluate the endodontic literature (Fryback and Thornbury 1991), and concluded that the expected ultimate benefit of CBCT to the endodontic patient is yet unclear, and is mainly limited to its technical and diagnostic accuracy efficacies, and thus, recommended a cautious and rational approach when considering $\mathrm{CBCT}$ for endodontic purposes (Rosen et al. 2015). These conclusions are in accordance with other recently published articles in endodontics (Kruse et al. 2015) and in other disciplines of dentistry (Rosen et al. 2017; EUROPEAN-COMMISSION 2012; Matzen and Wenzel 2014; Pittayapat et al. 2014; Kim et al. 2011).

It is therefore evident that the current literature assessing the benefit of CBCT to the endodontic patient is mainly limited to its technical efficacy (i.e., an inferior level of efficacy) and provides little information about its clinical efficacy (Rosen et al. 2017). Thus, the question regarding what is the ultimate benefit of CBCT to the endodontic patient remains un-answered.

\section{What else do we (do not) understand from the acquired CBCT data?}

In addition to the data on the endodontically involved tooth, $\mathrm{CBCT}$ scans also include additional adjacent areas that are usually not evident in routine intraoral radiographs (Kumar et al. 2015). The practitioner is required to examine the entire region that appears in the CBCT scan and report on any suspected abnormalities or pathologies (Rosen et al. 2017; Kumar et al. 2015; EUROPEANCOMMISSION 2012; ADA 2012; Brown et al. 2014). The daily use of $\mathrm{CBCT}$ by endodontic practitioners therefore raises concerns regarding the necessary training and experience required by the practitioner in order to efficiently evaluate the CBCT scans (Rosen et al. 2017; AAOMR and AAE 2010; Patel et al. 2015; ADA 2012; Brown et al. 2014). This diagnostic challenge may require comprehensive knowledge regarding the radiographic features of the head and neck anatomy and pathology that may be beyond the endodontic practitioner experiences (Brown et al. 2014), thus subjecting the patient to risks of undiagnosed pathologies and the practitioner to an ensuing medico-legal liability risk (Rosen et al. 2017; Brown et al. 2014; Friedland 2009; Givol et al. 2010).

\section{What do we (do not) know about the long-term risks of CBCT?}

CBCT yields a higher radiation dose than traditional intraoral radiography (ADA 2012). CBCTs use X-ray ionizing radiation (Rosen et al. 2017; EUROPEANCOMMISSION 2012; Bornstein et al. 2014; Brenner and Hall 2007) that potentially may harm the DNA leading to an ensuing risk of malignancy (EUROPEANCOMMISSION 2012). These potential harmful effects are unpredictable, and therefore, every exposure to X-rays should be considered as dangerous (Rosen et al. 2017; Rosen et al. 2015; Patel et al. 2015; EUROPEANCOMMISSION 2012; ADA 2012; Patel 2009; Patel et al. 2009). In addition, the risks may be significantly higher in children (EUROPEAN-COMMISSION 2012). Thus, strict considerations should be weighted prior to the use of CBCT, especially in children (Rosen et al. 2017; Pauwels et al. 2014; Petersen et al. 2015; Wu et al. 2015). The effective dose of CBCT scans is unpredictable and varies significantly depending on the field of view (FOV), the scanner type, and on many other acquisition parameters (Rosen et al. 2017; Patel et al. 2015; EUROPEANCOMMISSION 2012; Ludlow et al. 2015).

Thus, a careful and rational CBCT use should be based on a modern "better safe than sorry" preventive approach. This preventive approach advocates that preventive actions should be taken in order to disable potential harmful effect even when it is not certain to occur (Rosen et al. 2017; Rosen et al. 2015; AAOMR and AAE 2010; European-Environment-Agency 2001; Kheifets et al. 2001). In the context of $\mathrm{CBCT}$ use, the application of this preventive approach may be challenging since the immediate profit from the use of CBCT may seem significant (Rosen et al. 2015; AAOMR and AAE 2010; Berman and Hartwell 2006), and conversely, the harmful effects of the $\mathrm{CBCT}$ radiation exposure may not be obvious until years after the actual exposure (Rosen et al. 2017; Rosen et al. 2015; AAOMR and AAE 2010; Patel et al. 2015; Brenner and Hall 2007; Pauwels et al. 2014; Petersen et al. 2015; Wu et al. 2015; European-Environment-Agency 2001; Kheifets et al. 2001; Berrington de Gonzalez et al. 2009). 
Recent guidelines published regarding the use of cone beam computed tomography in Endodontics-2015/2016 Update AAE/AAOMR Joint Position Statement recommended periapical imaging be used for the evaluation of healing after nonsurgical and surgical endodontic treatment in the absence of clinical signs or symptoms. However, in the absence of clinical signs or symptoms, if limited FOV CBCT was the imaging modality of choice at the time of evaluation and treatment, CBCT was advised for the follow-up assessment. This recommendation was based on evidence that generally CBCT performed better for accurate diagnosis of complete and uneventful healing when compared with intraoral imaging (American Association of Endodontists. AAE and AAOMR joint position statement:use of cone beam computed tomography in endodontics-2015/ 2016 update. Available at: http://www.aae.org/uploadedfiles/ clinical_resources/guidelines_and_position_statements/conebeamstatement.pdf. Accessed 9 May 2017).

It may be concluded that the current literature, including recently published articles, raise substantial concerns regarding the long-term health risk associated with the use of $\mathrm{CBCT}$ in dentistry, advocating further research and a rational and cautious use of CBCT for endodontic proposes (Rosen et al. 2017; Pauwels et al. 2014; Petersen et al. 2015; Wu et al. 2015).

\section{Conclusions and a call for scientific evidence}

To-date, key questions regarding many aspects of the use of CBCT in endodontics still await to be answered, such as: what are the expected ultimate benefits of CBCT to the endodontic patient? What is the necessary training required by the practitioners in order to efficiently evaluate the CBCT scans? What are the potential and actual longterm radiation risks of CBCT scans? How these expected benefits and risks should be implemented as part of a cautious and rational clinical approach? (Rosen et al. 2017). Therefore, the scientific community is obligated to perform additional studies to elucidate these crucial matters, and endodontic practitioners must stay scientifically updated with the extensive ongoing research of the CBCT technology (Rosen et al. 2017; Rosen et al. 2015; ADA 2012).

In this thematic series, we call for manuscripts that discuss different aspects of the use of CBCT in endodontics. Potential topics include but are not limited to the following:

- Clinical applications of CBCT in endodontics.

- New technological developments of CBCT scanners and their applications in endodontics.

- Differential diagnosis to endodontic pathologies evaluated by CBCT.
- The training required by practitioners in order to efficiently use CBCT.

- The benefits and risks for the use of CBCT in endodontic.

- Case selection criteria for the use of CBCT in endodontics.

Authors' contributions

All authors drafted the manuscript. All authors participated in the design of the article. IT participated in its design and coordination. All authors read and approved the final manuscript.

\section{Competing interests}

The authors declare that they have no competing interests.

\section{Publisher's Note}

Springer Nature remains neutral with regard to jurisdictional claims in published maps and institutional affiliations.

\section{Author details}

'Department of Dentomaxillofacial Radiology, Faculty of Dentistry, Ankara University, 06500 Beşevler, Çankaya, Ankara, Turkey. ${ }^{2}$ Department of Endodontology, Maurice and Gabriela Goldschleger School of Dental Medicine, Tel Aviv University, Tel Aviv, Israel.

Received: 5 April 2017 Accepted: 15 May 2017

Published online: 06 June 2017

\section{References}

AAE and AAOMR Joint Position Statement. Use of Cone Beam Computed Tomography in Endodontics. 2015. Update 2015.

AAOMR, AAE, editors. AAE and AAOMR Joint Position Statement - Use of ConeBeam-Computed Tomography in Endodontics. 2010.

ADA, editor. The use of cone-beam computed tomography in dentistry. An advisory statement from the American Dental Association Council on Scientific Affairs. Chicago: The American Dental Association Council on Scientific Affairs; 2012

American Association of Endodontists. AAE and AAOMR joint position statement: use of cone beam computed tomography in endodontics-2015/2016 update. Available at: http://www.aae.org/uploadedfiles/clinical_resources/ guidelines_and_position_statements/conebeamstatement.pdf. Accessed 9 May 2017.

Berman LH, Hartwell GR. Diagnosis. In: Cohen S, Hargreaves KM, editors. Pathways of the Pulp. 9th ed. St. Louis: MOSBY; 2006. p. 2-39.

Berrington De Gonzalez A, Mahesh M, Kim KP, Bhargavan M, Lewis R, Mettler F, et al. Projected cancer risks from computed tomographic scans performed in the United States in 2007. Arch Intern Med. 2009;169(22):2071-7.

Bornstein MM, Scarfe WC, Vaughn VM, Jacobs R. Cone beam computed tomography in implant dentistry: a systematic review focusing on guidelines, indications, and radiation dose risks. Int J Oral Maxillofac Implants. 2014; 29(Suppl):55-77.

Brenner DJ, Hall EJ. Computed tomography —an increasing source of radiation exposure. N Engl J Med. 2007;357(22):2277-84.

Brown J, Jacobs R, Levring Jaghagen E, Lindh C, Baksi G, Schulze D, et al. Basic training requirements for the use of dental $C B C T$ by dentists: a position paper prepared by the European Academy of DentoMaxilloFacial Radiology. Dentomaxillofac Radiol. 2014:43(1):20130291.

Carrotte P. Endodontics: Part 2 Diagnosis and treatment planning. Br Dent J. 2004;197(5):231-8.

Del Fabbro M, Taschieri S, Lodi G, Banfi G, Weinstein RL. Magnification devices for endodontic therapy. Cochrane Database Syst Rev. 2015;12:CD005969.

Ee J, Fayad Ml, Johnson BR. Comparison of endodontic diagnosis and treatment planning decisions using cone-beam volumetric tomography versus periapical radiography. J Endod. 2014;40(7):910-6.

EUROPEAN-COMMISSION, editor. Radiation protection No 172 Cone beam CT for dental and maxillofacial radiology (Evidence-based guidelines). Luxembourg: the SEDENTEXCT project; 2012.

European-Environment-Agency; editor Late lessons from early warnings: the precautionary principle 1896-2000. Environmental issue report No 22; 2001; 
Copenhagen, Denmark: Luxembourg: Office for Official Publications of the European Communities, 2001.

Friedland B. Medicolegal issues related to cone beam ct. Semin Orthod. 2009;15:77-84.

Fryback DG, Thornbury JR. The efficacy of diagnostic imaging. Med Decis Making. 1991;11(2):88-94.

Givol N, Rosen E, Taicher S, Tsesis I. Risk management in endodontics. J Endod. 2010;36(6):982-4

Janner SF, Jeger FB, Lussi A, Bornstein MM. Precision of endodontic working length measurements: a pilot investigation comparing cone-beam computed tomography scanning with standard measurement techniques. J Endod. 2011;37(8):1046-51.

Jeger FB, Janner SF, Bornstein MM, Lussi A. Endodontic working length measurement with preexisting cone-beam computed tomography scanning: a prospective, controlled clinical study. J Endod. 2012;38(7): 884-8.

Kaeppler G, Cornelius CP, Ehrenfeld M, Mast G. Diagnostic efficacy of cone-beam computed tomography for mandibular fractures. Oral Surg Oral Med Oral Pathol Oral Radiol. 2013;116(1):98-104.

Kheifets LI, Hester GL, Banerjee GL. The precautionary principle and EMF: implementation and evaluation. J Risk Res. 2001;4(2):113-25.

Kim IH, Patel MJ, Hirt SL, Kantor ML. Clinical research and diagnostic efficacy studies in the oral and maxillofacial radiology literature: 1996-2005. Dentomaxillofac Radiol. 2011;40(5):274-81.

Krupinski EA, Jiang Y. Anniversary paper: evaluation of medical imaging systems. Med Phys. 2008:35(2):645-59.

Kruse C, Spin-Neto R, Wenzel A, Kirkevang LL. Cone beam computed tomography and periapical lesions: a systematic review analysing studies on diagnostic efficacy by a hierarchical model. Int Endod J. 2015;48(9):815-28.

Kumar M, Shanavas M, Sidappa A, Kiran M. Cone beam computed tomography—know its secrets. J Int Oral Health. 2015;7(2):64-8.

Liang YH, Jiang L, Chen C, Gao XJ, Wesselink PR, Wu MK, et al. The validity of cone-beam computed tomography in measuring root canal length using a gold standard. J Endod. 2013;39(12):1607-10.

Ludlow JB, Timothy R, Walker C, Hunter R, Benavides E, Samuelson DB, et al. Effective dose of dental CBCT-a meta analysis of published data and additional data for nine CBCT units. Dentomaxillofac Radiol. 2015;44(1): 20140197.

Matzen LH, Wenzel A. Efficacy of cone beam computed tomography for assessment of impacted mandibular third molars: a review based on a hierarchical model of evidence. Dentomaxillofac Radiol. 2014:20140189.

Metska ME, Liem VM, Parsa A, Koolstra JH, Wesselink PR, Ozok AR. Conebeam computed tomographic scans in comparison with periapical radiographs for root canal length measurement: an in situ study. J Endod. 2014:40(8):1206-9.

Mota de Almeida F, Knutsson K, Flygare L. The impact of cone beam computed tomography (CBCT) on the choice of endodontic diagnosis. Int Endod J. 2015: 48(6):564-72.

Patel S. New dimensions in endodontic imaging: Part 2. Cone beam computed tomography. Int Endod J. 2009;42(6):463-75.

Patel S, Dawood A, Whaites E, Pitt FT. New dimensions in endodontic imaging: part 1. Conventional and alternative radiographic systems. Int Endod J. 2009; 42(6):447-62.

Patel S, Durack C, Abella F, Shemesh H, Roig M, Lemberg K. Cone beam computed tomography in endodontics — a review. Int Endod J. 2015;48(1):3-15.

Pauwels R, Cockmartin L, Ivanauskaite D, Urboniene A, Gavala S, Donta C, et al. Estimating cancer risk from dental cone-beam CT exposures based on skin dosimetry. Phys Med Biol. 2014;59(14):3877-91.

Petersen LB, Olsen KR, Matzen LH, Vaeth M, Wenzel A. Economic and health implications of routine $\mathrm{CBCT}$ examination before surgical removal of the mandibular third molar in the Danish population. Dentomaxillofac Radiol. 2015;44(6):20140406.

Pittayapat P, Limchaichana-Bolstad N, Willems G, Jacobs R. Three-dimensional cephalometric analysis in orthodontics: a systematic review. Orthod Craniofac Res. 2014;17(2):69-91.

Rosen E, Taschieri S, Del Fabbro M, et al. The diagnostic efficacy of cone-beam computed tomography in endodontics: a systematic review and analysis by a hierarchical model of efficacy. J Endod. 2015;41(7):1008-14.

Rosen E, Allareddy V, Tsesis I. Case selection for the use of cone beam computed tomography in dentistry based on diagnostic efficacy and risk assessment. In: Rosen E, Nemcovsky CE, Tsesis I, editors. Evidence-Based Decision Making in
Dentistry: Multidisciplinary Management of the Natural Dentition. Switzerland: Springer International Publishing; 2017. p. 97-108.

Ustun Y, Aslan T, Sekerci AE, Sagsen B. Evaluation of the reliability of cone-beam computed tomography scanning and electronic apex locator measurements in working length determination of teeth with large periapical lesions. J Endod. 2016:42(9):1334-7.

Weinstein T, Rosano G, Del Fabbro M, Taschieri S. Endodontic treatment of a geminated maxillary second molar using an endoscope as magnification device. Int Endod J. 2010:43(5):443-50.

Wu TH, Lin WC, Chen WK, Chang YC, Hwang JJ. Predicting cancer risks from dental computed tomography. J Dent Res. 2015;94(1):27-35.

\section{Submit your manuscript to a SpringerOpen ${ }^{\circ}$ journal and benefit from:}

- Convenient online submission

- Rigorous peer review

- Open access: articles freely available online

- High visibility within the field

- Retaining the copyright to your article

Submit your next manuscript at $\boldsymbol{\sim}$ springeropen.com 